\begin{tabular}{|l|}
\hline Causes of bladder cancer \\
\hline - occupational exposure, eg, dyes \\
- cigarette smoking \\
- analgesic abuse \\
- chronic cystitis \\
immunosuppressive therapy, \\
eg, cyclophosphamide \\
pelvic irradiation \\
\hline
\end{tabular}

that conventional treatment of bladder cancer can be still successful in the presence of HIV infection. Another feature of interest in this patient is that he was relatively young for bladder cancer which may suggest a contribution of his HIV infection to the occurrence of the tumour.

In conclusion, the development of transitional cell carcinoma of the bladder in a patient

1 Biggar RJ. Cancer in acquired immunodeficiency syndrome: an epidemiological assessment. Semin Oncol 1990; 17: $251-60$.

2 Hoover R. Effect of drugs - immunosuppression. In: Hiat HH, Winsten JA. Origins of human cancer. Cold Spring Harbor, NY: Cold Spring Laboratory, 1977; pp 369-79.

3 Bernstein L, Hamilton AS. The epidemiology of AIDS related malignancies. Curr Opin Oncol 1993; 5: 822-30.

4 Spina M, Tirelli U. Human immunodeficiency virus as a risk factor in miscellaneous cancers. Curr Opin Oncol 1992; risk factor in

5 Crosato IM, Tirelli U, Vaccher G, et al. Solid tumors associated with HIV infection. Minerva Med 1993; 84: 89-
94.
Transitional cell carcinoma

disease of the old

- assocation with HIV infection not reported before

- conventional therapy is still successful when associated with HIV infection

with HIV infection may be fortuitous, however, it is possible that HIV infection may be implicated in the pathogenesis of the bladder tumour in our patient. As the HIV epidemic advances and survival of patients increases we might anticipate seeing more of these tumours in HIV-infected patients. Early diagnosis and treatment are essential for the good control of these malignancies.

6 Tessler AN, Catanese A. AIDS and germ cell tumors Urology 1987; 30: 203-4.

7 Levine AM. Cancer in AIDS. Curr Opin Oncol 1989; 1: $55-$

Nakamura S, Salahuddin SZ, Biberfeld P, et al. Kaposi's sarcoma cells: long term culture with growth factor from retrovirus-infected CD4+T cells. Science 1988; 242: 426retrov.

9 Catolona WJ. Urothelial tumors of the urinary tract. In: PC Walsh et al. eds. Campbell's urology, Philadelphia: Saunders, 1992; pp 1094-158.

North Staffordshire Hospital, Stoke on Trent, ST4 6QG, UK Department of

Surgery

JD Harrison

RM Kirby

Department of

Histopathology

C Musgrove

Correspondence to $\mathrm{Mr} \mathbf{R M}$ Kirby

Accepted 15 September 1995

\title{
Spindle cell stromal tumour of the rectum treated by restorative resection
}

\author{
JD Harrison, C Musgrove, RM Kirby
}

\begin{abstract}
Summary
Stromal tumours of the rectum and anal canal are rare, representing $0.02-0.03 \%$ of malignant neoplasms in the region. Current advice in their management is treatment by abdomino-perineal resection. We report a case of malignant spindle cell stromal tumour in which adequate clearance was obtained whilst preserving the anal sphincter, using a posterior parasacral approach.
\end{abstract}

Keywords: spindle cell stromal tumour, rectum, surgery

A 44-year-old man was admitted as an emergency with a two-month history of malaise, tenesmus and the passage of watery stools. This was associated with lower abdominal pain which was relieved by defaecation. Rectal examination revealed a posterior midline mass with ulceration of the overlying mucosa. A barium enema confirmed the presence of of a low rectal lesion (figure 1) with no evidence of a synchronous lesion. CT scan of the pelvis showed prominent thickening of the rectum, mainly in the pre-sacral space (figure 2). The lesion was thought to be intrinsic rather than extrinsic. There was no evidence of intra-abdominal metastases. At examination under anaesthesia a mobile tumour was found in the midline, $7 \mathrm{~cm}$ from the anal verge. Needle biopsies demonstrated a spindle cell tumour with little mitotic activity. The tumour stained positively for $\mathrm{S} 100$ protein favouring a diagnosis of a tumour of nerve sheath origin of uncertain malignant potential.

Surgical clearance was undertaken under general anaesthetic with the patient in a 'jackknife' position. The lesion, measuring $3.5 \mathrm{~cm}$, was exposed using a posterior approach excising the coccyx (as in a 'York-Mason' procedure). A full thickness excision of the posterior rectal wall including the lesion was 
carried out, with macroscopic clearance of the tumour (figure 3). The anal sphincter was not divided. A primary anastomosis was performed with a covering loop colostomy.

The patient made an uneventful recovery and was discharged after eleven days. The loop colostomy was closed six months later. He has full continence and remains disease free with no evidence of recurrence four and half years later.

The histological appearances of the resected specimen were similar to those seen in the needle biopsies (figures 4 and 5). These were of a spindle cell stromal tumour showing

Figure 1 Barium enema showing a mass anterior to the sacrum

Figure 2 CT scan of the pelvis showing thickening of the para-rectal tissues
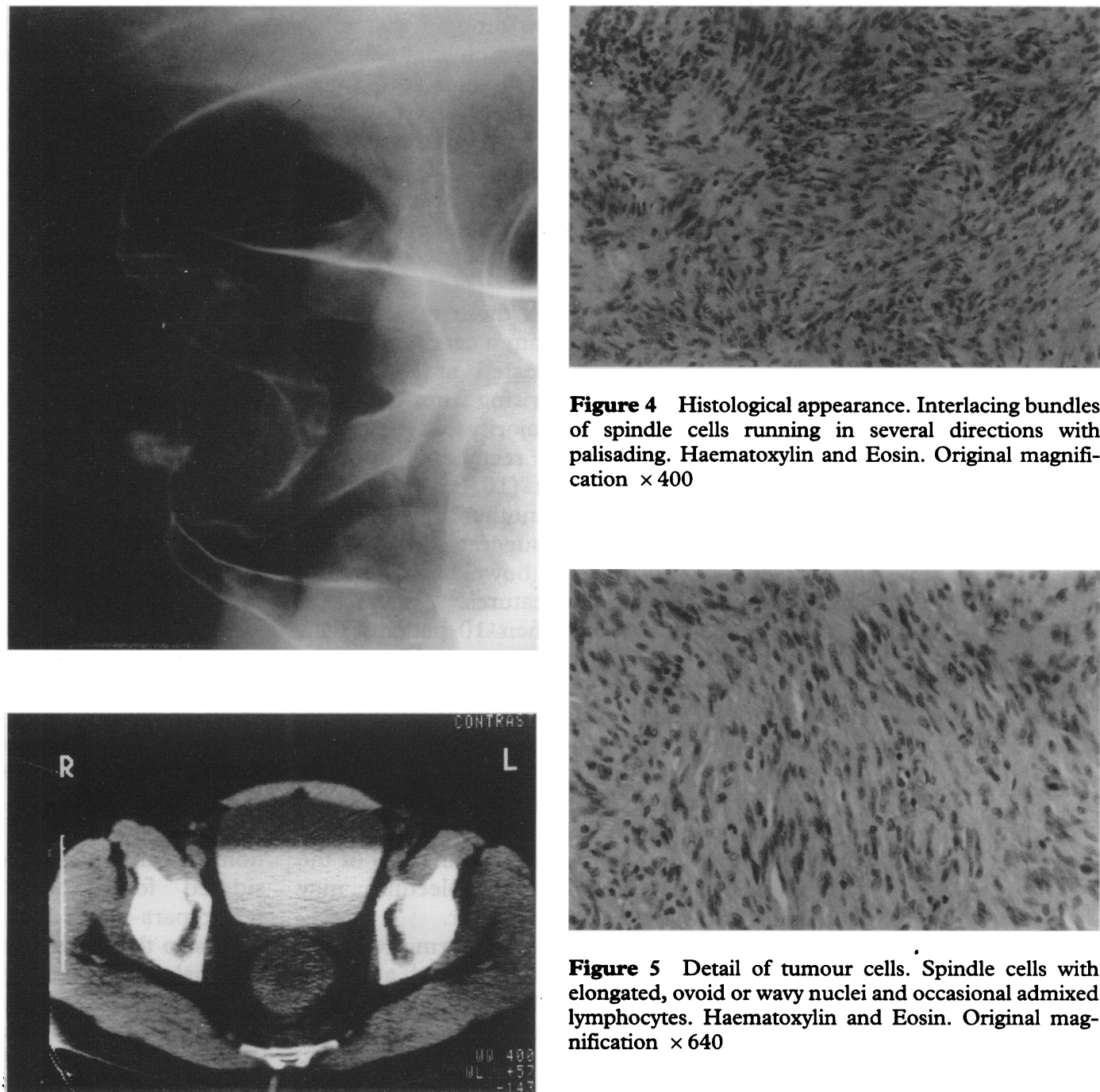

Figure 5 Detail of tumour cells. Spindle cells with elongated, ovoid or wavy nuclei and occasional admixed lymphocytes. Haematoxylin and Eosin. Original magnification $\times 640$

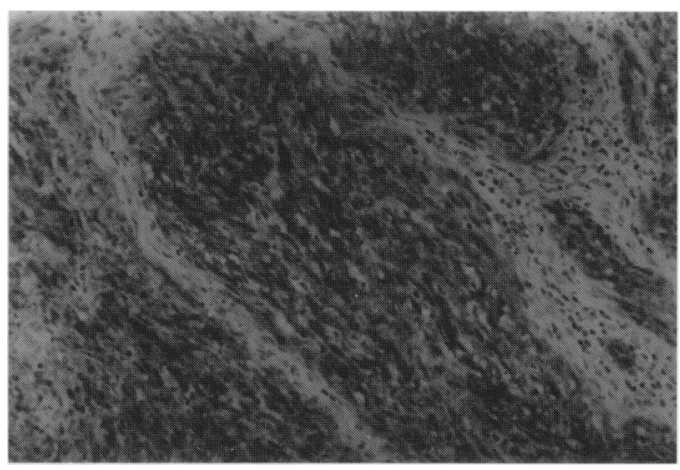

Figure 6 Immunohistochemistry. The tumour cells express S100 protein. Peroxidase-antiperoxidase technique. Original magnification $\times 400$
Figure 3 Transverse slice through excised rectal wall. The tumour has a 'pushing' margin and shows cavitary necrosis, extending into the bowel lumen. Original magnification $\times 3.25$

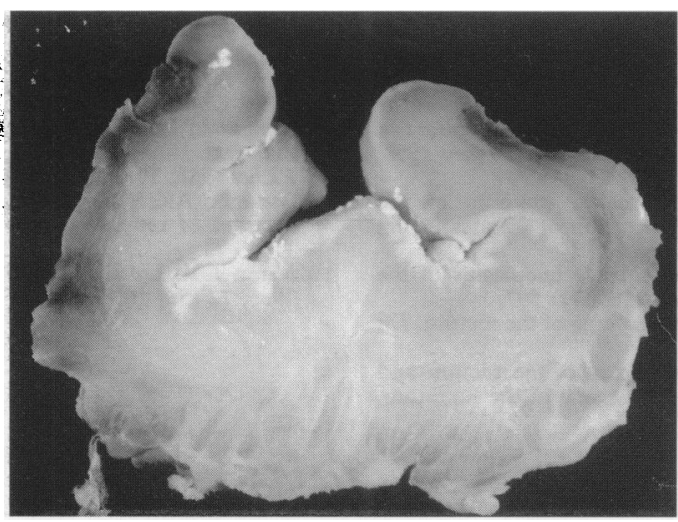

neural differentiation. This had an interlacing and focally palisading pattern and was composed of cells with blunt-ended or wavy nucle counts were on average one or two, but in one area six per 10 high power fields. Immunohistochemical studies showed strong positive for $\mathrm{S} 100$ and negative staining for CAM 5.2, CEA and actin (figure 6). There was widespread surface ulceration and cavitary muscularis propria with an overall pushing margin. The lateral, proximal and distal resection margins were tumour free.

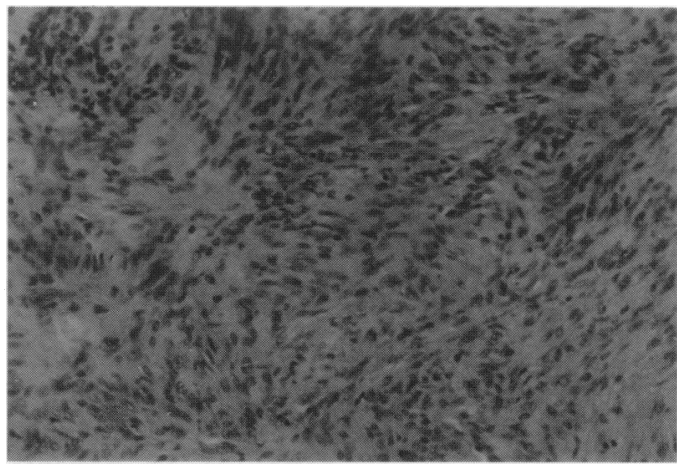

Figure 4 Histological appearance. Interlacing bundles of spindle cells running in several directions with palisading. Haematoxylin and Eosin. Original magnification $\times 400$ 


\section{Summary/learning points}

- spindle cell stromal tumours (smooth muscle tumours) of the rectum are rare (1 in 2-3000 rectal lesions)

- $50 \%$ may be regarded as malignant

- symptoms are similar to carcinoma

- histological differentiation between malignant/benign lesions may be difficult, especially in small biopsies

- local recurrence in malignant tumours is more common than metastatic spread

- standard techniques of excision are by abdomino-perineal resection

- posterior para-sacral approach local excision should provide adequate safe clearance

\section{Discussion}

Gastrointestinal stromal tumours have in the past usually been referred to as leiomyoma or leiomyosarcoma. It is now thought that most are of undifferentiated mesenchymal cell type although some have smooth muscle features and some appear to be of nerve sheath origin. ${ }^{1}$

Smooth muscle tumours of the rectum and anal canal are rare with an incidence of around one in $2-3000$ rectal lesions, and $50 \%$ are malignant. There is a slight male predominance and they tend to occur between the fifth and seventh decades. ${ }^{2-4}$

Symptoms arising from these tumours are similar to those arising from a carcinoma. In a series of 18 patients treated at St Mark's Hospital $^{4}$ with tumours arising from the rectal muscularis propria, the majority had symptoms of anal pain/tenesmus, rectal bleeding or alteration in bowel habit (10, seven and six patients, respectively). Another review of 89 cases in the literature suggested that pain, bleeding and alteration in bowel habit were the commonest presenting features. ${ }^{5}$ Anderson $e t$ $a l^{2}$ found that none of their 10 patients with leiomyoma had pain but seven of 10 patients with leiomyosarcoma had localised rectal pain, suggesting that this was a means of differentiating benign from malignant lesions.

The size of the tumour may also be a distinguishing feature, since leiomyosarcomata tend to be larger than the benign tumours and also overlying ulceration is seen in $50 \%$ of the malignant tumours. ${ }^{2}$ Severe bleeding may result from an ulcerating tumour.

These tumours are usually firm, rounded and usually deep to the submucosa, although they are rarely pedunculated. They are sharply circumscribed and the cut surface has a greyish-pink, whorled or 'watered silk' appearance. ${ }^{3,6}$ Histologically, cell derivation and malignant potential are difficult to assess; the

1 Hendrickson M, Kempson R. Smooth muscle tumours. In Whitehead R, ed. Gastrointestinal and oesophageal pathology Churchill Livingstone, 1989; pp 619-28.

2 Anderson P, Dockerty M, Buie L. Myomatous tumours of the rectum (leiomyomas and myosarcomas). Surgery 1950; 28: 642 .

3 Golden T, Stout A. Smooth muscle tumours of the gastrointestinal tract and retroperitoneal tissues. Surg Gynecol Obstet 1941; 73: 784 .

4 Walsh TH, Mann CV. Smooth muscle neoplasms of the rectum and anal canal. Brf Surg 1984; 71: 597.

5 Diamante M, Bacon $H$. Leiomyosarcoma of the rectum. Dis Colon Rectum 1967; 10: 347.

6 Kusminsky R, Bailey W. Leiomyomas of the rectum and anal canal: report of six cases and review of the literature. Dis Colon Rectum 1977; 20: 580. latter is dependent on cellularity, nuclear pleomorphism, anaplasia and mitotic index, as well as non-cavitary necrosis. Because there is overlap between the histological features seen in tumours which behave in a benign or malignant fashion ${ }^{1}$ confident prediction of behaviour not always possible. This is particularly true in small biopsies because of sampling error. A category designated 'uncertain malignant potential' is useful, but may be upgraded on examination of the whole specimen. Spread of tumour occurs most commonly to peritoneal surfaces, liver and lungs; lymph node spread has only been reported in three cases in the literature. ${ }^{4}$

The prognosis is dependent on the tumour grade, reflected in the mitotic index, ${ }^{7}$ but the overall outlook is poor despite aggressive surgical management. Other forms of primary or adjuvant treatment such as radiotherapy lack efficacy, probably due to the slow cell turnover in the tumour and its propensity to metastasise. ${ }^{2,4,5}$ Appelman ${ }^{8}$ suggests that tumours are likely to recur locally multiple times before they metastasise.

Because of the difficulty in determining malignant potential and the tendency to local recurrence it has been suggested that only small or pedunculated lesions should be dealt with by local excision while all others should be treated by abdomino-perineal rectal excision..$^{4,5}$ Despite this standard advice, new techniques are being assessed for local excision of carcinomata ${ }^{9}$ and these should now also be considered for stromal tumours. The posterior para-sacral approach ${ }^{10}$ allows adequate access to the lower rectum without damage to the anal sphincter. In our patient we were able to obtain a histologically satisfactory tumour clearance of a low lesion whilst preserving the anal sphincter. We would suggest that this approach should be considered in this type of lesion.

7 Evans H. Smooth muscle tumours of the gastrointestinal tract. A study of 56 cases followed for a minimum of 10 years. Cancer 1985; 56: 2242.

8 Appelman $H$. Smooth muscle tumours of the gastrointestinal tract. What we know that Stout didn't know. Am $\mathcal{F}$ Surg Pathol 1986; 10 (Suppl 1): 83.

9 Banerjee AK, Jehle EC, Shorthouse AJ, Buess G. Loca excision of rectal tumours (review). Br f Surg 1995; 82 1165-73.

10 Mann CV. Local resection of rectal tumours. Br f Surg 1985; 72 (Suppl): S57. 